\title{
Noble-Metal-Free Iron Nitride/Nitrogen-Doped Graphene Composite for the Oxygen Reduction Reaction
}

Tamás Varga, ${ }^{\dagger}$ Lívia Vásárhelyi, ${ }^{\dagger}$ Gergő Ballai, ${ }^{\dagger}$ Henrik Haspel, ${ }^{\dagger, \perp}$ Albert Oszkó, ${ }^{\ddagger}$ Ákos Kukovecz, ${ }^{\dagger, \S \odot ~}$ and Zoltán Kónya ${ }^{* \dagger}, \| \odot$

\author{
${ }^{\dagger}$ Department of Applied and Environmental Chemistry, University of Szeged, Rerrich Bela tér 1, H-6720 Szeged, Hungary \\ ${ }^{\ddagger}$ Department of Physical Chemistry and Materials Science, University of Szeged, Aradi Vértanúk tere 1, H-6720 Szeged, Hungary \\ ${ }^{\S}$ SZTE “Lendület” Porous Nanocomposites Research Group, Rerrich Béla tér 1, H-6720 Szeged, Hungary \\ "MTA-SZTE Reaction Kinetics and Surface Chemistry Research Group, Rerrich Béla tér 1, H-6720 Szeged, Hungary
}

\author{
Supporting Information
}

ABSTRACT: Considerable effort has been devoted recently to replace platinum-based catalysts with their non-noble-metal counterparts in the oxygen reduction reaction (ORR) in fuel cells. Nitrogen-doped carbon structures emerged as possible candidates for this role, and their earth-abundant metaldecorated composites showed great promise. Here, we report on the simultaneous formation of nitrogen-doped graphene and iron nitride from the lyophilized mixture of graphene oxide and iron salt by high-temperature annealing in ammonia atmosphere. A mixture of $\mathrm{FeN}$ and $\mathrm{Fe}_{2} \mathrm{~N}$ particles was formed with average particle size increasing from 23.4 to $127.0 \mathrm{~nm}$ and iron content ranging from 5 to $50 \mathrm{wt} \%$. The electrocatalytic oxygen reduction activity was investigated via the rotating disk electrode method in alkaline media. The highest current density of $3.65 \mathrm{~mA} \mathrm{~cm} \mathrm{c}^{-2}$ at $1500 \mathrm{rpm}$ rotation rate was achieved in the $20 \mathrm{wt} \%$ catalyst via the four-electrode reduction pathway, exceeding the activity of both the pristine iron nitride and the undecorated nitrogen-doped graphene. Since our catalysts showed improved methanol tolerance compared to the platinumbased ones, the formed non-noble-metal system offers a viable alternative to the platinum-decorated carbon black (Pt/CB) ORR catalysts in direct methanol fuel cells.

\section{INTRODUCTION}

Anthropogenic global warming is one of the greatest challenges of humankind today. Its effect could be attenuated by replacing fossil fuels with more sustainable resources. To this end, fuel cells can be of utmost importance as they can convert green fuels like hydrogen, methanol, ethanol, formic acid, etc. into electricity in a carbon neutral manner. ${ }^{1}$ The fuel is oxidized on the anode side separated by a thin polymeric membrane from the cathode side, where the oxygen reduction reaction (ORR) takes place. ORR also plays a crucial role at metal-air battery cathodes.

Porous carbon-supported platinum and platinum-based alloys were the traditional catalysts of choice for ORR in fuel cells. There are some practical issues with using platinumbased catalysts in fuel cells, though. Since oxygen reduction kinetics is sluggish, high amounts of costly precious-metal catalysts are needed. A further issue in direct methanol fuel cells (DMFCs) is the so-called methanol crossover through the ion-exchange membrane. Platinum catalyzes both ORR and methanol oxidation (MOR), and the $\mathrm{CO}$ intermediate of the latter reaction poisons the catalyst surface. This reduces the durability and performance of the catalyst and therefore the whole cell. ${ }^{2}$
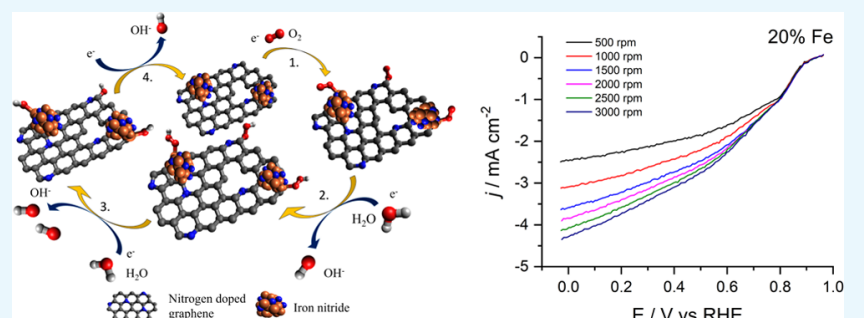

E/V vs RHE
Finding efficient ORR catalysts is challenging. Several nonnoble-metal catalyst systems have been proposed as platinum alternatives, like transition-metal carbides, ${ }^{3}$ oxides, ${ }^{4}$ chalcogenides, ${ }^{5}$ oxynitrides, ${ }^{2}$ or nitrides. ${ }^{6}$ In group $4-6$ transition-metal nitrides, the high ORR activity is caused by D-band contraction: the higher electron density near the Fermi level makes electron donation to the adsorbed oxygen easier. ${ }^{7}$ According to previous reports, the most active transition-metal nitrides are cobalt and iron nitrides. ${ }^{8-10}$ The fact that these catalysts usually work better in alkaline than in acidic media results in a higher interest from the alkaline membrane fuel cell field. $^{11}$

A further aspect to be considered regarding sustainability in green energy research is geopolitical availability. As it is not directly connected to materials science, it is often overlooked by scientists in this field, justifying the usage of cobalt instead of precious metals in their studies. It has to be emphasized that more than half of the world's cobalt mine production in 2017 ( $\sim 58.2 \%)$ came from one single country, while the next largest producers supplied at an order of magnitude lower annual rates

Received: October 4, 2018

Accepted: December 19, 2018

Published: January 3, 2019 


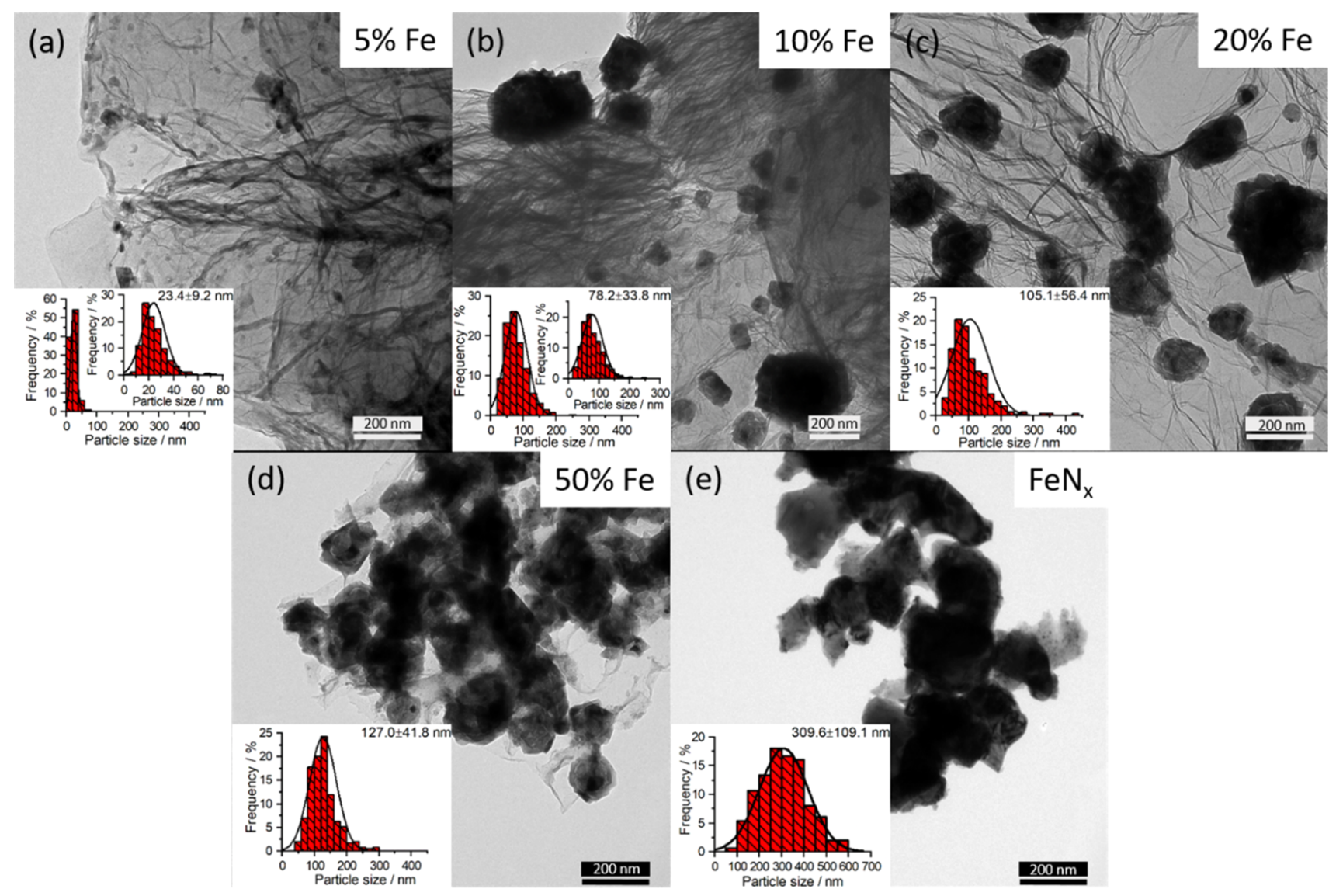

Figure 1. TEM images of the $\mathrm{FeN}_{x} / \mathrm{NG}$ samples with various weight percents of iron $(\mathrm{a}-\mathrm{d})$, and the pristine iron nitride particles synthesized without the presence of graphene oxide (e).

$(\sim 4-5 \%)$. Both the unstable political situation of the largest producer and the highly unbalanced nature of the cobalt market can threaten the global supply chain. Along with the rising demand for Li-ion battery cathodes, cobalt prices increased by almost a factor of 3 between November 2015 and January 2018 on the London Metal Exchange (LME) "owing to strong demand from consumers, limited availability of cobalt on the spot market, and an increase in metal purchases by investors" as concluded by the U.S. Geological Survey, Mineral Commodity Summaries, January 2018. ${ }^{12}$ Moreover, "growth in world refined cobalt supply was forecast to increase at a lower rate than that of world cobalt consumption, which was driven mainly by strong growth in the rechargeable battery and aerospace industries. As a result, the global cobalt supply was expected to remain limited in the near term". ${ }^{12}$ Therefore, iron seems to be a safer choice for producing non-noble-metal catalysts for the industry in the long run.

Several iron nitride synthesis methods have been reported in the literature so far. They are often based on the pyrolysis of transition-metal salts with nitrogen-containing molecules or polymeric organic precursors. Zhang et al. made porous polyaniline-derived $\mathrm{FeN}_{x} \mathrm{C} / \mathrm{C}$ catalysts by using iron chloride as the precursor of iron nitride and carbide. ${ }^{13}$ Wang et al. mixed an iron oxide/graphene aerogel composite with urea and thermally treated it in argon atmosphere to obtain an iron nitride/nitrogen-doped graphene (NG) composite. ${ }^{14}$ Chen et al. treated the mixture of iron chloride, glucose, and melamine first in nitrogen and then in ammonia/nitrogen atmosphere to get an iron nitride/nitrogen-doped carbon structure. ${ }^{15}$ Park et al. tested several precursors to synthesize iron nitride by ammonia treatment and found that the as-prepared nitride from iron(III) acetylacetonate $\left(\mathrm{Fe}(\mathrm{acac})_{3}\right)$ showed the best oxygen reduction reaction activity in contrast to that obtained from ferrocene $\left(\mathrm{C}_{10} \mathrm{H}_{10} \mathrm{Fe}\right)$, iron chloride $\left(\mathrm{FeCl}_{3}\right)$, iron sulfate $\left(\mathrm{FeSO}_{4}\right)$, and iron(II) acetylacetonate $\left(\mathrm{Fe}(\mathrm{acac})_{2}\right){ }^{16}$

Another type of non-precious metal ORR catalyst is the socalled metal-free catalysts. Typical representatives are carbon nitride, ${ }^{17,18}$ boron nitride, ${ }^{19,20}$ or heteroatom-doped (nitrogen or sulfur) carbon structures, like carbon nanotubes or graphene. ${ }^{21-26}$ Nitrogen-doped graphene (NG) is one of the most widely investigated heteroatom-doped carbon structures due to its advantageous physical-chemical properties and high ORR activity in both acidic and alkaline media. ${ }^{25,27,28}$ Density functional theory calculations by Zhang et al. revealed the role of carbon atoms with incorporated nitrogen atom neighbors in facilitating oxygen adsorption and hence promoting the ORR reaction. Pyridinic and pyrrolic nitrogen moieties were identified as key elements for the latter effects. ${ }^{29,30}$

Nitrogen-doped graphene composites can be synthesized using various approaches. Ma et al. and Tao et al. synthesized NG composites hydrothermally from either ammonia or urea mixed with graphene oxide, ${ }^{31,32}$ whereas $\mathrm{Zhu}$ et al. co-annealed graphene oxide with polypyrrole. ${ }^{33}$ Nitrogen-doped graphene can also be produced by chemical vapor deposition using methane as the carbon source and ammonia as the nitrogen source in the reaction. The resulting materials showed good ORR activity, accompanied with high stability and methanol tolerance. ${ }^{25}$ Zheng et al. used a hydrothermal approach to treat the mixture of urea and graphene oxide, and the as-prepared 

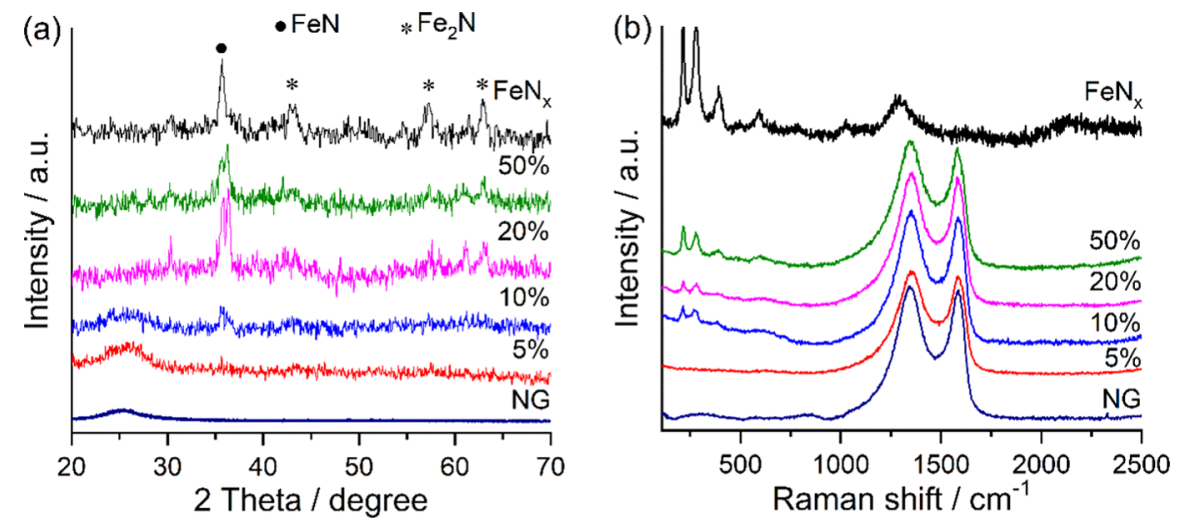

Figure 2. (a) X-ray diffractograms and (b) Raman spectra of the $\mathrm{FeN}_{x} / \mathrm{NG}$ samples with varying iron contents.
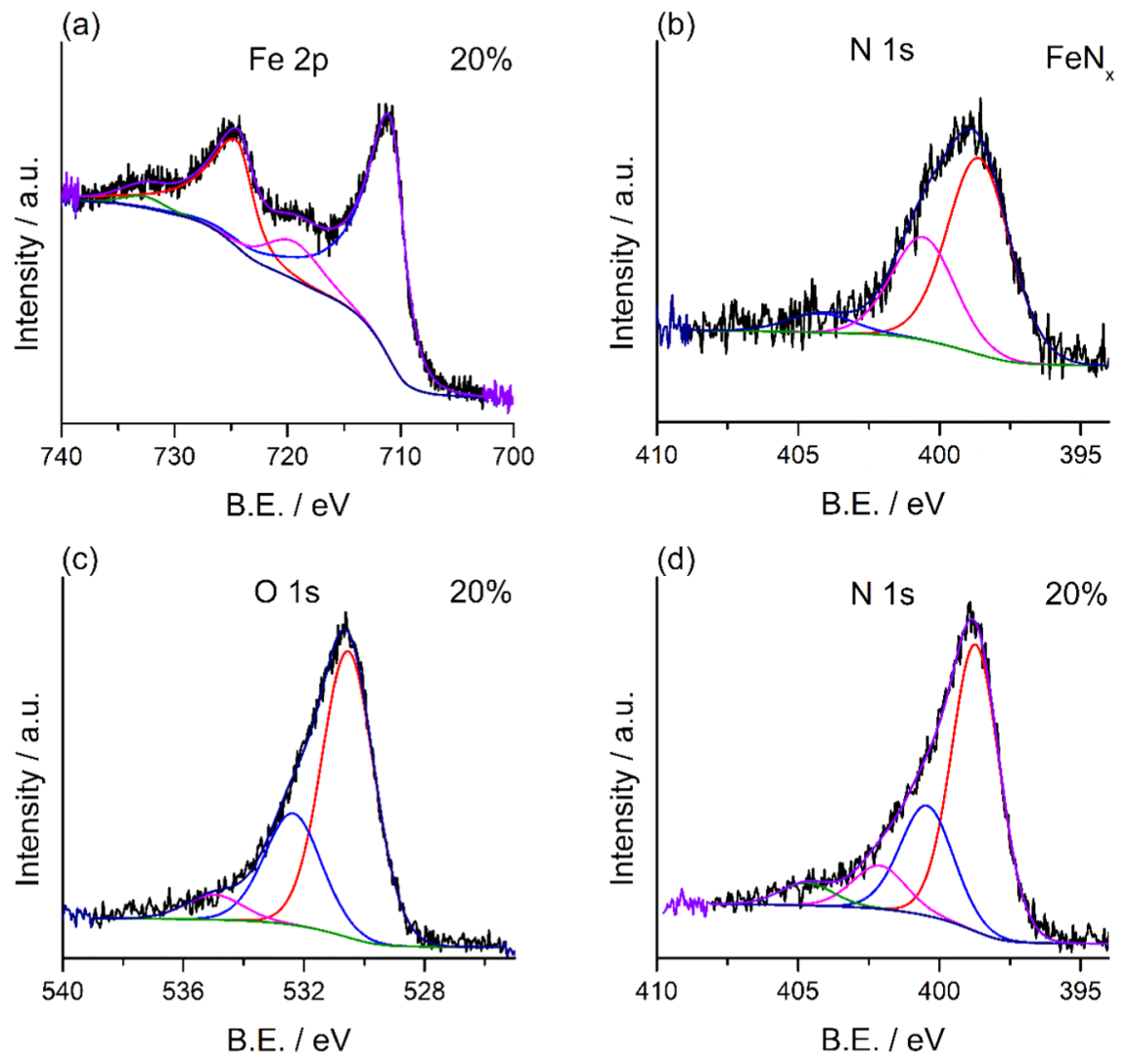

Figure 3. $\mathrm{Fe} 2 \mathrm{p}(\mathrm{a})$ spectrum of the $20 \mathrm{wt} \%$ iron-containing $\mathrm{FeN}_{x} / \mathrm{NG}$ sample. $\mathrm{N} 1 \mathrm{~s}$ (b) spectrum of the pure iron nitride particles synthesized without the presence of graphene oxide. $\mathrm{O} 1 \mathrm{~s}$ (c) and (d) $\mathrm{N} 1 \mathrm{~s}$ spectra of the $\mathrm{FeN}_{x} / \mathrm{NG}$ composite with 20 wt \% iron content.

NG exhibited a higher ORR activity than nondoped graphene. Even so, the activity of the widely used $\mathrm{Pt} /$ carbon black (CB) catalysts is difficult to surpass using non-noble-metal catalysts. $^{34}$ A further possible preparation pathway toward nitrogen-doped graphene is the reaction of ammonia with pristine graphene oxide at high temperatures. ${ }^{35}$

In this report, we present a simple, one-step synthesis method to prepare nitrogen-doped graphene decorated by iron nitride particles. To this end, the mixture of graphene oxide and iron(III) acetylacetonate with different ratios was annealed under ammonia atmosphere, resulting in the simultaneous formation of iron nitride and nitrogen-doped graphene.

Structural and morphological differences in the composites were investigated by X-ray diffraction (XRD), X-ray photoelectron spectroscopy (XPS), Raman spectroscopy, and transmission electron microscopy (TEM). The electrocatalytic activity of the as-prepared composites was studied using the rotating disk electrode ( $\mathrm{RDE}$ ) method in alkaline medium, and linear sweep voltammetry (LSV) was utilized to obtain electron-transfer numbers for the reaction. The methanol tolerance of the composite with the highest ORR activity was tested along with a noble-metal Pt/CB catalyst.

\section{RESULTS AND DISCUSSION}

Morphology. Transmission electron microscopy was used to characterize the morphology of the as-prepared composites. Figure $1 \mathrm{a}-\mathrm{d}$ shows that well-dispersed particles were grown onto the surface of the two-dimensional graphene surface after thermal treatment. The diameter of these particles increased with increasing iron content. According to the inset graphs in 

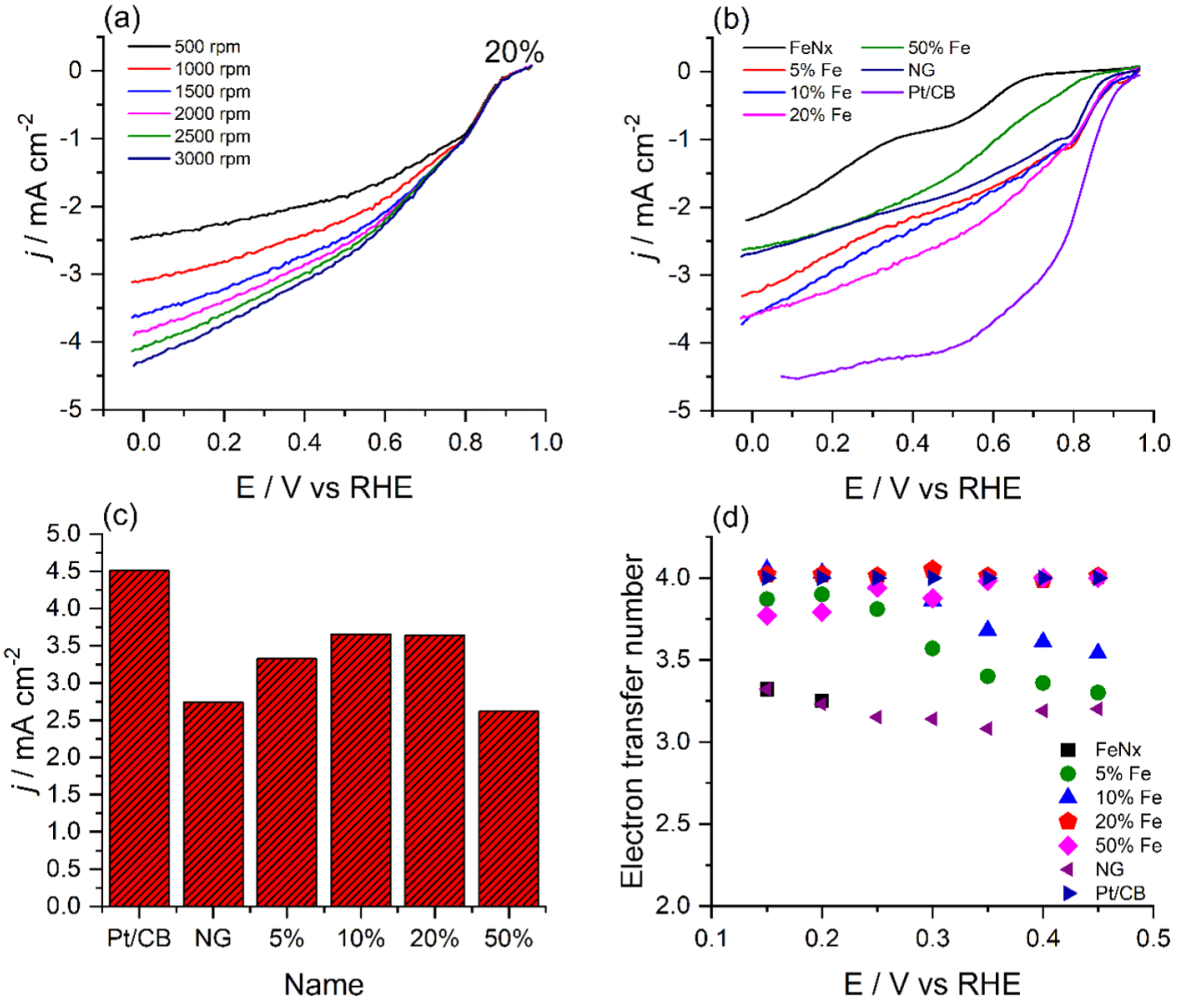

Figure 4. (a) LSV curves of the $20 \%$ iron-containing $\mathrm{FeN}_{x} / \mathrm{NG}$ using rotating disk electrode at various rotation rates. (b) Voltammograms recorded at fixed $1500 \mathrm{rpm}$ for the $\mathrm{FeN}_{x} / \mathrm{NG}$ and $\mathrm{Pt} / \mathrm{CB}$ composites on glassy carbon electrode (GCE). (c) Reduction current densities (at $0 \mathrm{~V}$ (vs $\mathrm{RHE})$ and $1500 \mathrm{rpm}$ ) and (d) electron-transfer numbers were determined from LSV measurements. Voltammograms were recorded in alkaline conditions $(0.1 \mathrm{M} \mathrm{KOH})$ applying a scan rate of $10 \mathrm{mV} \mathrm{s}^{-1}$.

Figure $1 \mathrm{a}-\mathrm{d}$, average particle sizes of $23.4 \pm 9.2,78.2 \pm 33.8$ $105.1 \pm 56.4$, and $127.0 \pm 41.8 \mathrm{~nm}$ were found for $5,10,20$, and $50 \mathrm{wt} \%$ iron contents, respectively. In the absence of graphene, $309.6 \pm 109.1 \mathrm{~nm}$ iron nitride particles were formed (Figure 1e).

Larger particles in Figure 1d were formed by the merging of primary grains. This is also discernible in Figure 1e, but with increased particle size and wider size distribution. This happens because the precursor salt can disperse well over the graphene oxide surface, which in turn yields more dispersed iron nitride nanoparticles during the salt decomposition under ammonia atmosphere.

Structure. The crystal structure of the composites, standalone iron nitride, and nitrogen-doped graphene was investigated with X-ray diffractometry. As Figure 2a shows, a mixture of $\mathrm{FeN}$ and $\mathrm{Fe}_{2} \mathrm{~N}$ was formed during the ammonia treatment. A reflection at $35.7^{\circ}$ can be assigned to the (111) plane of $\mathrm{FeN}^{36}{ }^{36}$ while the additional reflections at 43.1, 57.1, and $63.1^{\circ}$ correspond to the (011), (012), and (003) planes of $\mathrm{Fe}_{2} \mathrm{~N}$ (JCPDS 01-072-2126). ${ }^{37} \mathrm{~A}$ similar result was reported in a previous study by Yin et al. $^{38}$ The intensities of these reflections are lower in the case of low iron nitride content. The reflection at $26.6^{\circ}$ can be assigned to the layered structure of nitrogen-doped graphene. ${ }^{39}$

Raman spectra in Figure 2b show Stokes G- and D-bands at 1586 and $1347 \mathrm{~cm}^{-1}$, respectively. Both are characteristic features of carbonaceous materials. The D-band correlates with the degree of structural defects in the carbon structure, while the G-band is associated with the Raman active vibrations of $\mathrm{sp}^{2}$ carbon atoms, i.e., with the graphitic domains of the graphene structure. ${ }^{40}$ The intensity ratio of the D- and G- bands was found to be 1.02 in the case of NG. Somewhat higher, but constant values of $1.05,1.06,1.05$, and 1.06 occurred in the case of composites with 5, 10, 20, and 50 wt \% iron contents, respectively. These values are in good agreement with the literature data on nitrogen-doped graphene composites. ${ }^{31}$ The observed ratios imply that the amount of defects and/or the incorporated nitrogen atoms in the graphene structure could be higher in the composites than in the pristine nitrogen-doped graphene. This result agrees well with the literature data. Choi et al. showed that the presence of iron could promote the incorporation of nitrogen into the carbon structure. ${ }^{41}$ Further peaks were observed at 217.9, 280.8 , and $391.2 \mathrm{~cm}^{-1}$. These peaks correspond to the iron nitride phase. ${ }^{42}$

The initial condition of the catalysts was characterized by ex situ X-ray photoelectron spectroscopy. Some of the measured spectra are depicted in Figure 3. The high-resolution Fe $2 p$ spectrum of the $20 \%$ composite in Figure 3 a shows peaks at 711.1 and $724.6 \mathrm{eV}$. These correspond to the $2 \mathrm{p}_{1 / 2}$ and $2 \mathrm{p}_{3 / 2}$ photoelectron lines of $\mathrm{Fe}(\mathrm{III})$, while their corresponding satellite peaks can also be observed at 719.7 and $733.2 \mathrm{eV}$. These Fe(III) species can interact with nitrogen or oxygen to form $\mathrm{FeN}_{x}$ or iron oxides. ${ }^{43}$ The same was obtained in other iron nitride composites, as it can be seen in Figure S1a,c,e,g. Although it refers to an iron oxide phase, it was not detected in the XRD patterns (Figure 2a), as most likely, only a thin layer was formed due to surface oxidation. Similar findings were reported in other systems too. ${ }^{37,44}$ The proof of nitride formation can be seen in Figure 3b, though. Since the N 1s peak of iron nitride was recorded in the absence of graphene, it was deconvoluted into three features at binding energies of 

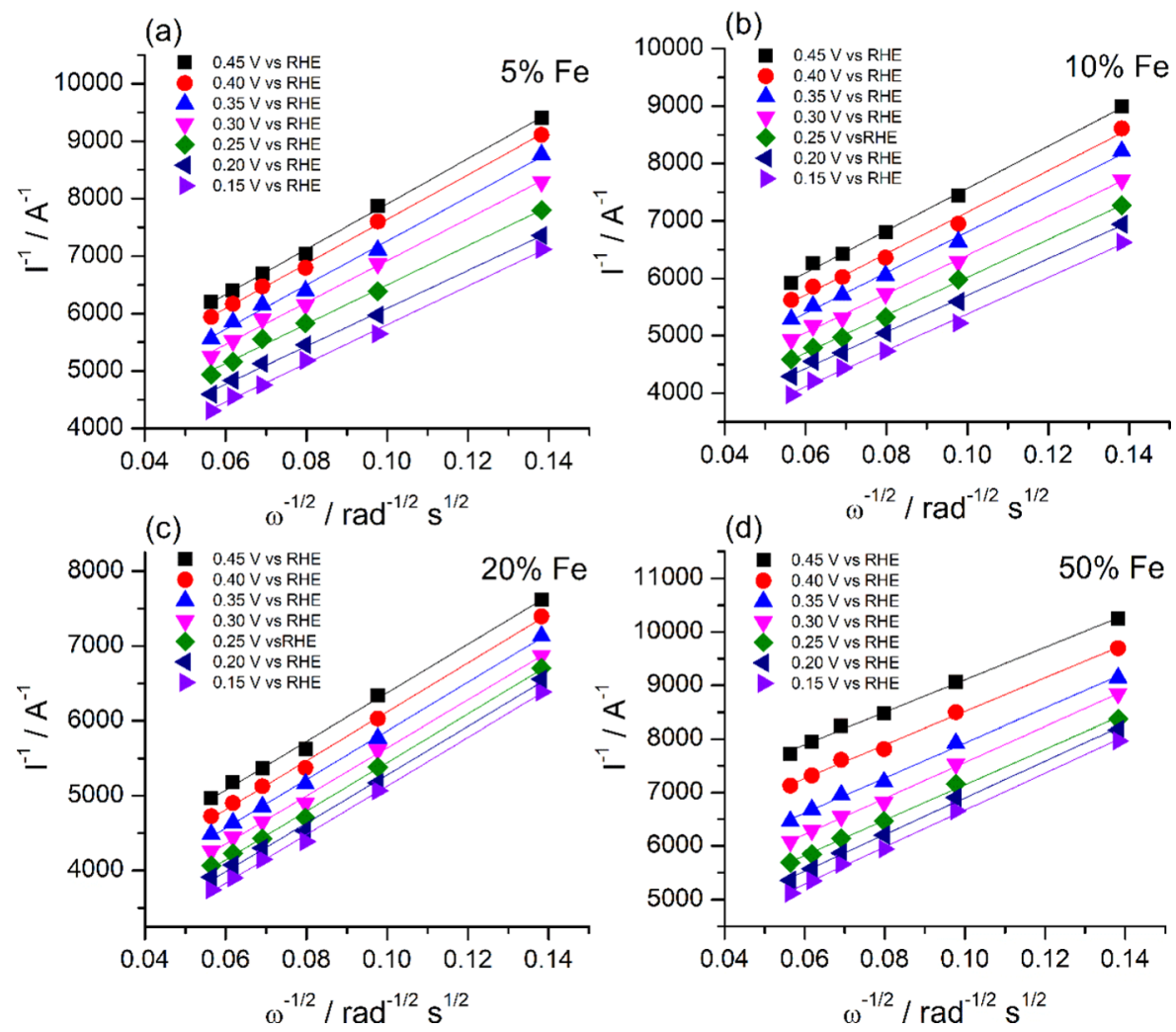

Figure 5. Koutecký-Levich plots determined from linear sweep voltammetry. Composites with (a) 5\%, (b) $10 \%$, (c) $20 \%$, and (d) $50 \%$ iron contents were deposited onto a glassy carbon electrode.

398.6, 400.6, and $404.1 \mathrm{eV}$. The first peak corresponds to the bonding between the nitrogen and iron atoms, while the second and third peaks indicate the presence of adsorbed ammonia and nitrogen oxide species, respectively. ${ }^{44}$ The iron/ nitrogen ratio in iron nitride was calculated to be $1.7: 1$. This agrees well with the $\mathrm{XRD}$ analysis above and confirms the formation of the $\mathrm{FeN}-\mathrm{Fe}_{2} \mathrm{~N}$ mixture.

$\mathrm{O} 1 \mathrm{~s}$ spectra show a hydroxyl feature at 532.3 and the sign of carboxyl groups at $534.8 \mathrm{eV}$ binding energies in Figure 3c. The latter peaks could appear in the spectra because of water and carbon dioxide molecules adsorbed on the surface, and/or they could also be due to various functional groups of graphene oxide that remained intact during the ammonia treatment. ${ }^{45,46}$ A further peak at $530.5 \mathrm{eV}$ corresponds to the iron-oxygen interaction $^{37}$ and thus serves as an additional proof for oxide layer formation on the particle surface. Azuma et al. investigated the surface of a sputtered transition-metal nitride and found that there was a thin surface layer containing oxygenated groups. When the surface was etched with $\mathrm{Ar}^{+}$ions, the $\mathrm{O} 1 \mathrm{~s}$ peak was weakened. ${ }^{47}$ Similar differences in the $\mathrm{O} 1 \mathrm{~s}$ spectra for the nitrogen-doped graphene, iron nitridedecorated composites, and iron nitride particles can be seen in Figure S2.

Various nitrogen moieties can be formed by the incorporation of nitrogen into the carbon structure during the ammonia treatment of graphene oxide. Figure $3 \mathrm{~d}$ shows the deconvoluted $\mathrm{N}$ 1s spectrum of iron nitride/nitrogen-doped graphene composite with 20 wt $\%$ iron content. Features at 398.7 and $400.7 \mathrm{eV}$ can be assigned to the pyrrolic- and pyridinic-type nitrogen moieties, respectively. Several theoretical and experimental studies revealed that the incorporation of pyrrolic- and pyridinic-type nitrogen species improves the
ORR activity of carbon structures. ${ }^{25,29,30,48,49}$ According to previous reports and the small difference between the binding energies of pyridinic-type and iron-bonded nitrogen, we concluded that the peak at $400.7 \mathrm{eV}$ should also include the contribution of nitrogen, which was bonded to iron. ${ }^{50}$ The additional peaks at higher binding energy evidence the presence of oxidized pyridinic-type nitrogen moieties. ${ }^{51}$ Similar results were obtained from the $\mathrm{N}$ 1s spectra of nitrogen-doped graphene and composites with different iron contents in Figure $\mathrm{S} 1 \mathrm{~b}, \mathrm{~d}, \mathrm{f}, \mathrm{h}$. The atomic ratio of nitrogen and carbon in the graphene structure was calculated from the XPS images and is depicted in Figure S3. N/C increased from 0.098 to 0.122 as the iron content of the composite increased from 5 to $20 \%$. However, the N/C ratio dropped upon any further increase in the iron content. It was also documented in the literature in, e.g., iron oxide/carbon nanotube ${ }^{41}$ or iron oxide/nitrogendoped graphene composites. ${ }^{52}$

Electrocatalytic Activity. Alkaline electrocatalytic oxygen reduction activity was tested in $0.1 \mathrm{M} \mathrm{KOH}$ using cyclic voltammetry (CV) (Figures S4 and S7a) and linear sweep voltammetry (LSV). Figure 4a shows that the current density was increasing with increasing rotation rate in the $20 \mathrm{wt} \%$ iron-containing sample, and Figure S5 demonstrates the same trend for the other working electrodes. Linear sweep voltammograms at $1500 \mathrm{rpm}$ rotation rate are compared in Figure $4 \mathrm{~b}$. The onset potentials of the 5, 10, and $20 \mathrm{wt} \%$ iron content samples were similar and around $0.90 \mathrm{~V}$ (vs reversible hydrogen electrode (RHE)) - slightly more positive than that of the pristine nitrogen-doped graphene $(0.87 \mathrm{~V}$ (vs RHE)). Further increase in the iron content, however, decreased the onset potential: 0.84 and $0.69 \mathrm{~V}$ (vs RHE) were found for the $50 \mathrm{wt} \%$ iron containing composite and for pristine, graphene 


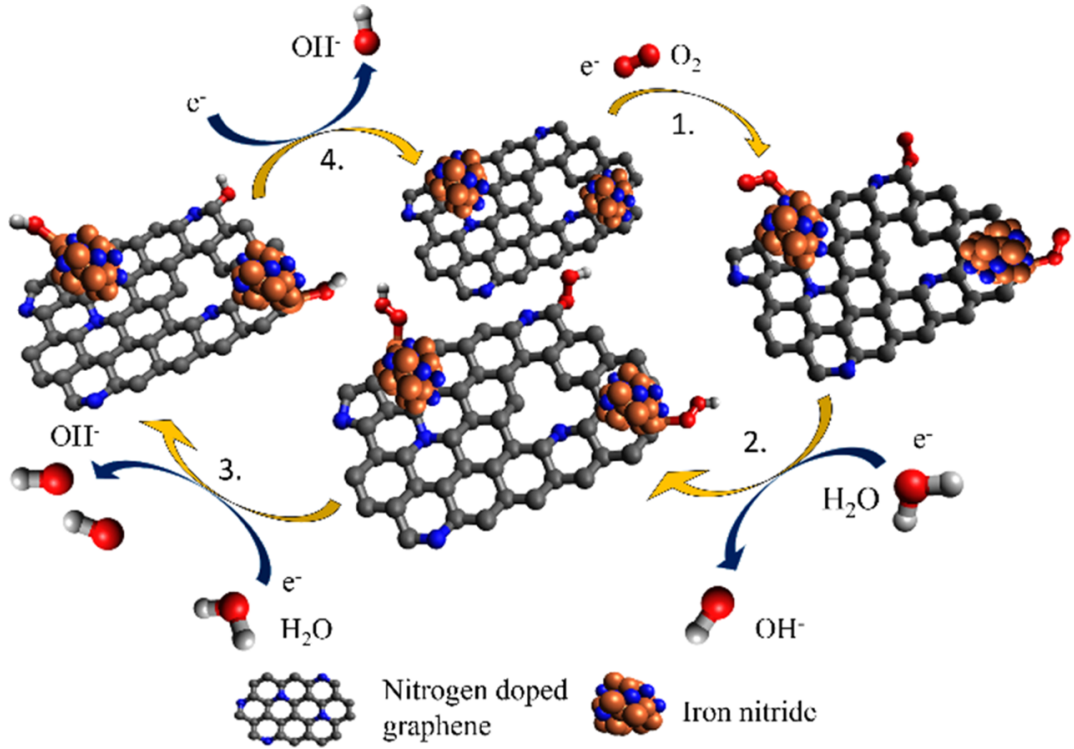

Figure 6. Schematic of the possible ORR mechanism in $\mathrm{FeN}_{x} / \mathrm{NG}$ composite via the four-electron pathway.

oxide-free iron nitride, respectively. The obtained reduction current densities at $1500 \mathrm{rpm}$ rotation rate (recorded at $0 \mathrm{~V}$ (vs RHE)) are summarized in Figure 4c. The composites with 5,10 , and 20 wt $\%$ iron contents have higher current densities than the stand-alone nitrogen-doped graphene $(2.70 \mathrm{~mA}$ $\left.\mathrm{cm}^{-2}\right)$ and iron nitride $\left(2.21 \mathrm{~mA} \mathrm{~cm}{ }^{-2}\right)$. The highest reduction current density $\left(3.65 \mathrm{~mA} \mathrm{~cm}^{-2}\right)$ was reached at 10 and $20 \mathrm{wt}$ $\%$ iron contents. However, even higher current densities were achieved in the $20 \mathrm{wt} \%$ iron-containing composite at more positive potentials between 0.1 and $0.8 \mathrm{~V}$ (vs RHE). The performance of the $5 \mathrm{wt} \%$ iron-containing composite (3.32 $\mathrm{mA} \mathrm{cm}{ }^{-2}$ ) falls between that of the iron-free and the best performing catalysts. A similar trend manifests in the onset potentials: the $50 \mathrm{wt} \%$ iron composite featured a lower current density than the other composites with lower iron contents. These results imply that the ORR activity of iron nitride can be improved by decreasing its particle size. Nitrogen-doped graphene as a support material can prevent particle aggregation besides exhibiting an inherent ORR activity as well. These findings are consistent with the X-ray photoelectron spectroscopy results. The $\mathrm{N} / \mathrm{C}$ atomic ratio of nitrogen-doped graphene was higher at $20 \mathrm{wt} \%$ iron content, which in turn implied that there may be more incorporated nitrogen atoms in the graphene structure. This resulted in a higher number of catalytically active sites in the graphene surface.

However, the reduction current density of our most promising composite (recorded at $0 \mathrm{~V}$ (vs RHE) at 1500 $\mathrm{rpm}$ rotation rate) was still lower than that of the most commonly used $\mathrm{Pt} / \mathrm{CB}$ catalyst $\left(4.45 \mathrm{~mA} \mathrm{~cm}{ }^{-2}\right.$ ) (seen in Figure $4 \mathrm{c}$ ). Furthermore, the onset potential was slightly more positive in the case of $\mathrm{Pt} / \mathrm{CB}$-modified GCE (0.96 V (vs $\mathrm{RHE}$ )), but considering the price difference between $\mathrm{Pt} / \mathrm{CB}$ and $\mathrm{FeN}_{x} / \mathrm{NG}$, our composites certainly represent a competitive value proposition.

Further information about the ORR mechanism was obtained via the Koutecký-Levich analysis of the linear sweep voltammograms recorded at different rotation rates (Figures 4a and S5 and S7b). Electron-transfer numbers were determined by using the Koutecký-Levich equation

$$
\frac{1}{j}=\frac{1}{j_{\mathrm{k}}}+\frac{1}{j_{\mathrm{d}}}=\frac{1}{n F k c_{\mathrm{O}_{2}}^{\mathrm{b}}}+\frac{1}{0.62 n F D_{\mathrm{O}_{2}}^{2 / 3} \nu^{-1 / 6} c_{\mathrm{O}_{2}}^{\mathrm{b}} \omega^{1 / 2}}
$$

where $j$ is the apparent current density, $j_{\mathrm{k}}$ and $j_{\mathrm{d}}$ are the kinetic and diffusion-limited current densities, respectively, $n$ is the number of transferred electron of one oxygen molecule, $F$ is the Faraday constant, $k$ is the rate constant, the $c_{\mathrm{O}_{2}}^{\mathrm{b}}$ and $D_{\mathrm{O}_{2}}$ values are $1.2 \times 10^{-6} \mathrm{~mol} \mathrm{~cm}{ }^{-3}$ and $1.9 \times 10^{-5} \mathrm{~cm}^{2} \mathrm{~s}^{-1}$, the oxygen concentration and diffusion coefficient in $0.1 \mathrm{M} \mathrm{KOH}$ at $23{ }^{\circ} \mathrm{C}$, respectively, ${ }^{53} \nu$ is the solution's kinetic viscosity (8.9 $\left.\times 10^{-3} \mathrm{~cm}^{2} \mathrm{~s}^{-1}\right),{ }^{54}$ and $\omega$ denotes the electrode's angular velocity in rad $\mathrm{s}^{-1} .55$

The Koutecký-Levich plots of the sample series were determined from LSV measurements on glassy carbon RDE electrodes and are depicted in Figure 5 at different potentials. The fitted linear lines of the plots refer to the first-order kinetics of the reaction (Koutecký-Levich plots of the other samples are depicted in Figures S6 and S7c), ${ }^{56}$ while off-zero intercepts indicate a mixed kinetic diffusion control. ${ }^{57}$ Figure $4 \mathrm{~d}$ summarizes the corresponding electron-transfer numbers. The pristine iron nitride and the nitrogen-doped graphene yielded 3.2, while higher values were obtained in the case of composites. The onset potential for $\mathrm{FeN}_{x}$ in the linear voltammograms can be seen at more negative potentials; therefore, measurements were done only in the lower potential regime. By changing the potential from 4.5 to $1.5 \mathrm{~V}$ (vs RHE), the electron-transfer number increased from 3.3 to 3.8 and from 3.5 to 4.0 for 5 and $10 \mathrm{wt} \%$ iron contents, respectively. This indicates that increasing the overpotential favors the fourelectron process over the two-electron pathway. The fourelectron pathway was observed at higher overpotentials in the 10 wt \% sample and in almost the whole investigated potential range in the $20 \mathrm{wt} \%$ composite. This result is comparable with the behavior of our as-prepared $\mathrm{Pt} / \mathrm{CB}$ composite and other commercially used platinum-based catalysts. ${ }^{58,59}$

To investigate the role of iron nitride in the composites, the iron nitride was removed from the surface of the nitrogendoped graphene by etching the $20 \mathrm{wt} \%$ iron-containing sample in a $4 \mathrm{M} \mathrm{HCl}$ solution. Figure S8a shows the TEM image of 
the composite after etching (curve " $20 \% \mathrm{Fe}$ e"). The successful removal of the iron nitride particles was confirmed by $\mathrm{XRD}$, as only the reflections corresponding to nitrogendoped graphene can be seen in the diffractogram in Figure S8b. The ORR activity of the etched sample was compared to that of the $20 \mathrm{wt} \%$ composite and the pristine nitrogen-doped graphene in Figure S9. LSV curves of the modified GCE electrodes recorded at $1500 \mathrm{rpm}$ rotation rate (Figure S9a) show that although the current density decreased slightly due to the etching process, it was still higher than in the case of nitrogen-doped graphene prepared in the absence of iron nitride. Furthermore, the onset potential showed a negative shift from 0.9 to $0.85 \mathrm{~V}$ (vs RHE) after removing the iron nitride particles. A similar trend was observed for the electrontransfer number insofar as it decreased after the removal of the metal nitride phase (3.6). However, the latter value is still higher than in the case of nitrogen-doped graphene prepared in the absence of the metal precursor (3.2) (Figure S9b). The deteriorating performance, i.e., the drop in current density and electron-transfer number and the shift in the onset potential, clearly exposes the importance of iron nitride in the ORR activity of the composite. A stronger $\mathrm{Fe}-\mathrm{N}-\mathrm{C}$ interaction between the metal nitride and the support was formed during the synthesis, and this synergistic effect further improved the electrocatalytic ORR activity. ${ }^{60}$

There is an ongoing debate on the location and chemical nature of the active sites in $\mathrm{M}-\mathrm{N}-\mathrm{C}$ ORR catalysts, and thus, several theories allow in recent literature. It was suggested that the iron species only participate in the active $\mathrm{C} / \mathrm{N}$ site formation during catalyst preparation, but they do not work as ORR active sites. ${ }^{9}$ According to other studies, including the present work, the activity of the nonprecious metal-containing nitrogen-doped carbon catalysts decreased after the removal of the metallic part in an acidic treatment. This clearly underlines the importance of the metal nitride in the electrocatalytic reduction of oxygen. ${ }^{9,61}$ The higher ORR activity of the etched sample compared to that of the pristine nitrogen-doped graphene can be explained with the increased amount of nitrogen in the graphene structure. Lai et al. showed that the increased pyridinic nitrogen content in the carbon structure converts the mechanism from the two-electron process to the four-electron pathway. ${ }^{62}$

A possible oxygen reduction reaction mechanism with a four-electron process is summarized in Figure 6. After the adsorption of an oxygen molecule onto the surface of the nitride nanoparticle, the oxygen-oxygen bond is weakened due to the strong interaction between the transition metal and oxygen. The first electron-transfer step results in the formation of an adsorbed $\mathrm{O}_{2}^{-}$species. In the next step, peroxide is formed on the surface in the reaction of adsorbed $\mathrm{O}_{2}{ }^{-}$with a water molecule. In the third reaction step, adsorbed $\mathrm{OH}$ is formed, which then desorbs as hydroxide ion in the final step, closing the reaction cycle. It is worth mentioning that this mechanism can take place on the nitrogen-doped graphene surface as well. Since the incorporation of nitrogen atoms can substantially modify the charge and spin distribution at the neighboring carbon atoms, the latter become more prone to the interaction with oxygen molecules. This in turn results in higher ORR activity, as it is well known from the literature. ${ }^{63,64}$

Another reaction pathway could be the so-called outersphere mechanism, which is also possible in alkaline media. In this case, the solvated oxygen molecules are in the outer Helmholtz plane, and a noncovalent hydrogen bond is formed between the oxygen and the adsorbed $\mathrm{OH}$, which acts as an outer-sphere bridge in this case. However, this pathway promotes the two-electron pathway. ${ }^{65}$

A further important technological aspect of ORR catalysts is their resistance against impurities. In direct methanol fuel cells, methanol is used as fuel, which diffuses through the polymeric membrane separating the anode and cathode compartments. This so-called methanol crossover reduces the ORR activity and therefore reduces the efficiency of the whole fuel cell. The methanol resistance of our most active $20 \mathrm{wt} \%$ iron-containing composite was tested in a chronoamperometric test. In Figure 7 , the relative current $\left(I / I_{0}\right)$, i.e., the ratio of the current

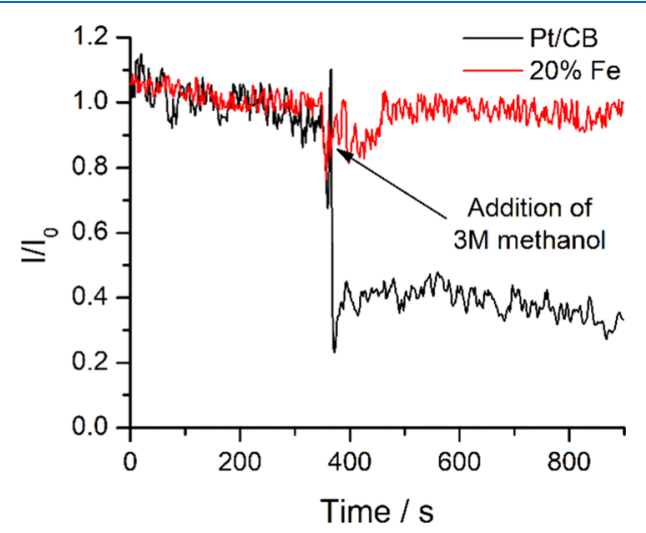

Figure 7. Alkaline $(0.1 \mathrm{M} \mathrm{KOH})$ chronoamperometric methanol tolerance ORR response at $0.51 \mathrm{~V}$ (vs RHE) of commercial $\mathrm{Pt} / \mathrm{CB}$ catalyst and the $20 \mathrm{wt} \% \mathrm{Fe}$-containing composite deposited onto a glassy carbon electrode.

measured at a given time and the initial current of the composite, is compared to that of commercial Pt/CB catalystmodified GCE electrode.

After the addition of methanol to the electrolyte solution at $360 \mathrm{~s}$, a sharp drop in the relative current was observed in the case of the Pt/CB-modified electrode. The electrocatalytic activity decreased steeply in the presence of methanol due to the activity of $\mathrm{Pt} / \mathrm{CB}$ toward the methanol oxidation reaction (MOR). ${ }^{66}$ On the other hand, there was no significant change in the relative current of our non-noble-metal composite, thus evidencing considerably higher methanol tolerance compared to the widely used precious-metal $\mathrm{Pt} / \mathrm{CB}$ catalyst.

\section{CONCLUSIONS}

A single-step synthesis was developed to obtain iron nitride nanoparticle-decorated nitrogen-doped graphene catalysts for the electrochemical oxygen reduction reaction (ORR). The composites were synthesized via the high-temperature annealing of a lyophilized mixture of graphene oxide and iron(III) acetylacetonate under ammonia atmosphere. A mixture of $\mathrm{FeN}$ and $\mathrm{Fe}_{2} \mathrm{~N}$ was formed during the thermal treatment, with an increasing particle size from 23.4 to 127.0 $\mathrm{nm}$ by increasing the iron content in the 5-50 wt \% range. Increasing amounts of pyridinic- and pyrrolic-type nitrogen moieties were successfully incorporated into the graphene structure along with the increase in the iron content. The electrocatalytic activity of the catalyst was tested in a threeelectrode system in alkaline media using the rotating disk electrode technique at different rotation rates. The highest current density $\left(3.65 \mathrm{~mA} \mathrm{~cm}{ }^{-2}\right.$ at $\left.1500 \mathrm{rpm}\right)$ was reached in the $20 \mathrm{wt} \%$ iron-containing composite, outperforming both 
the pristine iron nitride and the nitrogen-doped graphene. The composite catalyzes the oxygen reduction via the four-electron pathway, as evidenced from the determination of the electrontransfer number. Furthermore, the catalyst exhibited high methanol tolerance compared to a commercial platinum-based system. The latter benefit is particularly relevant for handling cathode-side methanol oxidation, one of the major drawbacks of precious-metal ORR fuel cell catalysts in direct methanol fuel cells (DMFCs). Additional advantages of the suggested system include refraining from both the high price of platina group metals and the limited availability of cobalt, a widely studied metal in non-precious-metal ORR catalyst.

\section{EXPERIMENTAL SECTION}

Synthesis of Graphene Oxide. The modified Hummers method was used in the graphene oxide synthesis. ${ }^{67}$ Typically, $4.5 \mathrm{~g}$ of graphite powder and sodium nitrate $\left(\mathrm{NaNO}_{3}\right)$ were mixed with $210 \mathrm{~mL}$ of c.c. $\mathrm{H}_{2} \mathrm{SO}_{4}$ under vigorous stirring for $30 \mathrm{~min}$. Then, $27 \mathrm{~g}$ of $\mathrm{KMnO}_{4}$ was added to the solution with continuous cooling in an ice bath. After $24 \mathrm{~h}$ stirring, $500 \mathrm{~mL}$ of $\mathrm{H}_{2} \mathrm{O}$ and $10 \mathrm{~mL}$ of $50 \% \mathrm{H}_{2} \mathrm{O}_{2}$ were poured into the solution and stirred for another $2 \mathrm{~h}$. The product was washed with deionized (DI) water to obtain sulfate-free supernatant and then dried at $80{ }^{\circ} \mathrm{C}$ overnight.

Synthesis of Iron Nitride/Nitrogen-Doped Graphene Oxide. In a typical synthesis, graphene oxide and iron(III) acetylacetonate were mixed in DI water. To obtain composites with $5,10,20$, and 50 wt \% iron loadings, 33.3, 70.2, 158.2, and $632.1 \mathrm{mg}$ of iron salts were weighed in, respectively. The mixture was stirred overnight, followed by lyophilization with a Labconco freeze dryer at $0.014 \mathrm{mbar}$ and $-55^{\circ} \mathrm{C}$. Ammonia $(120 \mathrm{sccm})$ heat treatment at $600{ }^{\circ} \mathrm{C}$ was then applied for $1 \mathrm{~h}$, purging the furnace with ammonia to prevent oxygen contamination in the product. Bare iron nitride and nitrogen-doped graphene were also prepared for comparison. Pristine iron nitride was prepared via annealing of iron(III) acetylacetonate powder, while nitrogen-doped graphene was prepared according to the previous recipe of the composites, but without adding the iron precursor. Untreated graphene oxide was subjected to the same lyophilization and annealing steps. To investigate the role of iron nitride in the catalytic activity, the as-prepared composite with $20 \%$ iron content was annealed in a round-bottom flask under continuous stirring in a $4 \mathrm{M} \mathrm{HCl}$ solution for $48 \mathrm{~h}$ to remove the iron nitride from the graphene surface.

Characterization Methods. Sample morphology was studied by an FEI Tecnai $\mathrm{G}^{2} 20 \mathrm{X}$ Twin transmission electron microscope (TEM) at a $200 \mathrm{kV}$ accelerating voltage. Samples were drop-cast onto a copper mounted holey carbon film from isopropyl alcohol suspension. The diameter of 50-50 iron nitride particles was measured in 10 representative TEM images to determine the corresponding particle size distribution. The powder X-ray diffractograms were recorded by a Rigaku Miniflex II diffractometer using $\mathrm{Cu} \mathrm{K} \alpha$ radiation at a scan speed of $4^{\circ} \mathrm{min}^{-1}$. Raman spectra were measured using $532 \mathrm{~nm}$ laser excitation at $5 \mathrm{~mW}$ power (Thermo Scientific DXR Raman Microscope), averaging 10 scans from 200 to $3500 \mathrm{~cm}^{-1}$ Raman shift at $1 \mathrm{~cm}^{-1}$ resolution. X-ray photoelectron spectroscopy (XPS) was done using the Al anode's $\mathrm{K} \alpha$ radiation (SPECS instrument with a PHOIBOS 150 MCD 9 hemispherical analyzer), where the analyzer was used in the fixed analyzer transmission mode with a $20 \mathrm{eV}$ pass energy and the X-ray gun at $210 \mathrm{~W}(14 \mathrm{kV}, 15 \mathrm{~mA})$.
Electrode Preparation. For all electrochemical measurements, a $3 \mathrm{~mm}$ glassy carbon electrode (purchased from BASi) was used. The carbon surface was thoroughly cleaned before any subsequent surface modification. After carefully polishing it with a $0.05 \mu \mathrm{m}$ diameter alumina slurry, it was rinsed and sonicated in ethanol and ion-exchanged water, followed by drying in air at room temperature. For the RDE samples, a homogeneous suspension of $1.0 \mathrm{mg}$ of sample in a mixture of $250 \mu \mathrm{L}$ of ethanol/water (1:1 volume ratio) and $10 \mu \mathrm{L}$ of $5 \mathrm{wt}$ $\%$ Nafion solution was prepared via ultrasonication. A $15.0 \mu \mathrm{L}$ aliquot from the resulted suspension was then drop-cast onto the pretreated glassy carbon electrode and dried at room temperature. The same method was used to prepare the $10 \mathrm{wt}$ $\%$ Pt-containing Pt/CB-modified CGE electrode, which served as an ORR benchmark catalyst.

Electrochemical Measurements. The ORR activity of the composites was investigated in a three-electrode configuration, where the surface-modified glassy carbon electrode and a platinum wire served as the working and counter electrodes, respectively. The working electrode potential was determined against a $\mathrm{Ag} / \mathrm{AgCl}(3 \mathrm{M} \mathrm{NaCl}$, $\mathrm{BASi}$ ) reference electrode. The potential was varied during cyclic and linear sweep voltammetry (CV and LSV) measurements (ACM Instruments GILL AC electrochemical workstation) from 0 to $-1000 \mathrm{mV}$ against $\mathrm{Ag} / \mathrm{AgCl}(3 \mathrm{M} \mathrm{NaCl})$ at a scan rate of $10 \mathrm{mV} \mathrm{s}^{-1}$. During the rotating disk electrode (RDE) LSV measurements, the rotation rate was varied between 500 and $3000 \mathrm{rpm}$. Background correction was done to all voltammograms, and the resulted corrected data were used for further calculations. All measurements were carried out in nitrogen- and oxygen-saturated $0.1 \mathrm{M} \mathrm{KOH}$ solutions at room temperature $\left(23^{\circ} \mathrm{C}\right)$.

Potentials against the reversible hydrogen electrode (RHE) were used throughout the study and calculated according to the well-known equation

$$
E(\text { vs RHE })=E+E_{\mathrm{Ag} / \mathrm{AgCl}}(\text { vs SHE })+0.059 \mathrm{~V} \cdot \mathrm{pH}
$$

where $E$ is the measured potential against the reference electrode and $E_{\mathrm{Ag} / \mathrm{AgCl}}$ (vs $\mathrm{SHE}$ ) is its standard electrode potential $(0.209 \mathrm{~V})$ at $23{ }^{\circ} \mathrm{C}$. SHE denotes the standard hydrogen electrode.

Methanol tolerance was investigated in a $0.1 \mathrm{M} \mathrm{KOH}$ solution with continuous oxygen bubbling via chronoamperometry at $0.51 \mathrm{~V}$ (vs RHE). After continuously recording the current for $6 \mathrm{~min}, 1 \mathrm{~mL}$ of $3 \mathrm{M}$ methanol solution was quickly added to the system and the corresponding change was recorded.

\section{ASSOCIATED CONTENT}

\section{Supporting Information}

The Supporting Information is available free of charge on the ACS Publications website at DOI: 10.1021/acsomega.8b02646.

XPS, CV, and LSV results of the composites, and TEM, XRD, and LSV data for the etched $\mathrm{FeN}_{x} / \mathrm{NG}$ composites (PDF)

\section{AUTHOR INFORMATION}

\section{Corresponding Author}

*E-mail: konya@chem.u-szeged.hu. 


\section{ORCID $\odot$}

Ákos Kukovecz: 0000-0003-0716-9557

Zoltán Kónya: 0000-0002-9406-8596

\section{Present Address}

${ }^{\perp}$ Division of Physical Sciences and Engineering, KAUST Catalysis Center (KCC), King Abdullah University of Science and Technology (KAUST), Thuwal 23955-6900 Saudi Arabia (H.H.).

\section{Notes}

The authors declare no competing financial interest.

\section{ACKNOWLEDGMENTS}

Financial support from the Hungarian National Research Development and Innovation Office through grants GINOP2.3.2-15-2016-00013, NKFIH OTKA K120115 (Z.K.), and K126065 (Á.K.) is gratefully acknowledged.

\section{REFERENCES}

(1) Steele, B. C. H.; Heinzel, A. Materials for fuel-cell technologies. Nature 2001, 414, 345-352.

(2) Cao, B.; Veith, G. M.; Diaz, R. E.; Liu, J.; Stach, E. A.; Adzic, R. R.; Khalifah, P. G. Cobalt molybdenum oxynitrides: synthesis, structural characterization, and catalytic activity for the oxygen reduction reaction. Angew. Chem., Int. Ed. 2013, 52, 10753-10757.

(3) Sun, T.; Jiang, Y.; Wu, Q.; Du, L.; Zhang, Z.; Yang, L.; Wang, X.; $\mathrm{Hu}, \mathrm{Z}$. Is iron nitride or carbide highly active for oxygen reduction reaction in acidic medium? Catal. Sci. Technol. 2017, 7, 51-55.

(4) Yu, J.; Chen, G.; Sunarso, J.; Zhu, Y.; Ran, R.; Zhu, Z.; Zhou, W.; Shao, Z. Cobalt Oxide and Cobalt-Graphitic Carbon Core-Shell Based Catalysts with Remarkably High Oxygen Reduction Reaction Activity. Adv. Sci. 2016, 3, No. 1600060.

(5) Wang, H.; Liang, Y.; Li, Y.; Dai, H. Co1-xS-Graphene Hybrid: A High-Performance Metal Chalcogenide Electrocatalyst for Oxygen Reduction. Angew. Chem., Int. Ed. 2011, 50, 10969-10972.

(6) Jing, S.; Luo, L.; Yin, S.; Huang, F.; Jia, Y.; Wei, Y.; Sun, Z.; Zhao, Y. Tungsten nitride decorated carbon nanotubes hybrid as efficient catalyst supports for oxygen reduction reaction. Appl. Catal., B 2014, 147, 897-903.

(7) Ham, D. J.; Lee, J. S. Transition Metal Carbides and Nitrides as Electrode Materials for Low Temperature Fuel Cells. Energies 2009, 2, 873-899.

(8) Raj, C. R.; Samanta, A.; Noh, S. H.; Mondal, S.; Okajima, T.; Ohsaka, T. Emerging new generation electrocatalysts for the oxygen reduction reaction. J. Mater. Chem. A 2016, 4, 11156-11178.

(9) Gewirth, A. A.; Varnell, J. A.; DiAscro, A. M. Nonprecious Metal Catalysts for Oxygen Reduction in Heterogeneous Aqueous Systems. Chem. Rev. 2018, 118, 2313-2339.

(10) Wu, G.; Zelenay, P. Nanostructured Nonprecious Metal Catalysts for Oxygen Reduction Reaction. Acc. Chem. Res. 2013, 46, 1878-1889.

(11) Dekel, D. R. Review of cell performance in anion exchange membrane fuel cells. J. Power Sources 2018, 375, 158-169.

(12) U.S. Geological Survey. https://minerals.usgs.gov/minerals/ pubs/commodity/cobalt/mcs-2018-cobal.pdf, January 2018.

(13) Zhang, J.; He, D.; Su, H.; Chen, X.; Pan, M.; Mu, S. Porous polyaniline-derived $\mathrm{FeN}_{\mathrm{x}} \mathrm{C} / \mathrm{C}$ catalysts with high activity and stability towards oxygen reduction reaction using ferric chloride both as an oxidant and iron source. J. Mater. Chem. A 2014, 2, 1242-1246.

(14) Wang, S.; Yu, D.; He, X. A facile strategy to fabricate nitrogendoped graphene aerogel-supported $\mathrm{Fe} 3 \mathrm{~N}$ nanoparticles as efficient electrocatalysts for the oxygen reduction reaction. New J. Chem. 2017, $41,1755-1764$

(15) Chen, Z.-Y.; Li, Y.-N.; Lei, L.-L.; Bao, S.-J.; Wang, M.-Q.; Heng-Liu, H.-L.; Zhao, Z.-L.; Xu, M.-w. Investigation of Fe2N@ carbon encapsulated in $\mathrm{N}$-doped graphene-like carbon as a catalyst in sustainable zinc-air batteries. Catal. Sci. Technol. 2017, 7, 56705676.

(16) Park, M.; Lee, J.; Hembram, K.; Lee, K.-R.; Han, S.; Yoon, C.; Nam, S.-W.; Kim, J. Oxygen Reduction Electrocatalysts Based on Coupled Iron Nitride Nanoparticles with Nitrogen-Doped Carbon. Catalysts 2016, 6, 86.

(17) Qin, Y.; Li, J.; Yuan, J.; Kong, Y.; Tao, Y.; Lin, F.; Li, S. Hollow mesoporous carbon nitride nanosphere/three-dimensional graphene composite as high efficient electrocatalyst for oxygen reduction reaction. J. Power Sources 2014, 272, 696-702.

(18) Zheng, Y.; Jiao, Y.; Jaroniec, M.; Jin, Y.; Qiao, S. Z. Nanostructured Metal-Free Electrochemical Catalysts for Highly Efficient Oxygen Reduction. Small 2012, 8, 3550-3566.

(19) Chen, X.; Chang, J.; Yan, H.; Xia, D. Boron Nitride Nanocages as High Activity Electrocatalysts for Oxygen Reduction Reaction: Synergistic Catalysis by Dual Active Sites. J. Phys. Chem. C 2016, 120, 28912-28916.

(20) Uosaki, K.; Elumalai, G.; Noguchi, H.; Masuda, T.; Lyalin, A.; Nakayama, A.; Taketsugu, T. Boron nitride nanosheet on gold as an electrocatalyst for oxygen reduction reaction: theoretical suggestion and experimental proof. J. Am. Chem. Soc. 2014, 136, 6542-6525.

(21) Alexeyeva, N.; Shulga, E.; Kisand, V.; Kink, I.; Tammeveski, K. Electroreduction of oxygen on nitrogen-doped carbon nanotube modified glassy carbon electrodes in acid and alkaline solutions. J. Electroanal. Chem. 2010, 648, 169-175.

(22) Chen, L.; Cui, X.; Wang, Y.; Wang, M.; Qiu, R.; Shu, Z.; Zhang, L.; Hua, Z.; Cui, F.; Wei, C.; Shi, J. One-step synthesis of sulfur doped graphene foam for oxygen reduction reactions. Dalton Trans. 2014, 43, 3420-3423.

(23) Jiang, S.; Ma, Y.; Jian, G.; Tao, H.; Wang, X.; Fan, Y.; Lu, Y.; $\mathrm{Hu}, \mathrm{Z}$; Chen, Y. Facile Construction of $\mathrm{Pt}-\mathrm{Co} / \mathrm{CNx}$ Nanotube Electrocatalysts and Their Application to the Oxygen Reduction Reaction. Adv. Mater. 2009, 21, 4953-4956.

(24) Li, M.; Zhang, L.; Xu, Q.; Niu, J.; Xia, Z. N-doped graphene as catalysts for oxygen reduction and oxygen evolution reactions: Theoretical considerations. J. Catal. 2014, 314, 66-72.

(25) Qu, L.; Liu, Y.; Baek, J.-B.; Dai, L. Nitrogen-Doped Graphene as Efficient Metal-Free Electrocatalyst for Oxygen Reduction in Fuel Cells. ACS Nano 2010, 4, 1321-1326.

(26) Yang, Z.; Yao, Z.; Li, G.; Fang, G.; Nie, H.; Liu, Z.; Zhou, X.; Chen, X.; Huang, S. Sulfur-Doped Graphene as an Efficient Metal-free Cathode Catalyst for Oxygen Reduction. ACS Nano 2012, 6, 205211.

(27) Wong, W. Y.; Daud, W. R. W.; Mohamad, A. B.; Kadhum, A. A. H.; Loh, K. S.; Majlan, E. H. Recent progress in nitrogen-doped carbon and its composites as electrocatalysts for fuel cell applications. Int. J. Hydrogen Energy 2013, 38, 9370-9386.

(28) Wang, T.; Chen, Z.-X.; Chen, Y.-G.; Yang, L.-J.; Yang, X.-D.; Ye, J.-Y.; Xia, H.-P.; Zhou, Z.-Y.; Sun, S.-G. Identifying the Active Site of N-Doped Graphene for Oxygen Reduction by Selective Chemical Modification. ACS Energy Lett. 2018, 3, 986-991.

(29) Zhang, L.; Niu, J.; Dai, L.; Xia, Z. Effect of microstructure of nitrogen-doped graphene on oxygen reduction activity in fuel cells. Langmuir 2012, 28, 7542-7550.

(30) Zhang, L.; Xia, Z. Mechanisms of Oxygen Reduction Reaction on Nitrogen-Doped Graphene for Fuel Cells. J. Phys. Chem. C 2011, $115,11170-11176$.

(31) Ma, J.; Habrioux, A.; Luo, Y.; Ramos-Sanchez, G.; Calvillo, L.; Granozzi, G.; Balbuena, P. B.; Alonso-Vante, N. Electronic interaction between platinum nanoparticles and nitrogen-doped reduced graphene oxide: effect on the oxygen reduction reaction. J. Mater. Chem. A 2015, 3, 11891-11904.

(32) Tao, L.; Dou, S.; Ma, Z.; Shen, A.; Wang, S. Simultaneous Pt deposition and nitrogen doping of graphene as efficient and durable electrocatalysts for methanol oxidation. Int. J. Hydrogen Energy 2015, 40, 14371-14377.

(33) Zhu, J.; Xiao, M.; Zhao, X.; Li, K.; Liu, C.; Xing, W. Nitrogendoped carbon-graphene composites enhance the electrocatalytic 
performance of the supported Pt catalysts for methanol oxidation. Chem. Commun. 2014, 50, 12201-12203.

(34) Zheng, B.; Wang, J.; Wang, F.-B.; Xia, X.-H. Synthesis of nitrogen doped graphene with high electrocatalytic activity toward oxygen reduction reaction. Electrochem. Commun. 2013, 28, 24-26.

(35) Li, X.; Wang, H.; Robinson, J. T.; Sanchez, H.; Diankov, G.; Dai, H. Simultaneous Nitrogen Doping and Reduction of Graphene Oxide. J. Am. Chem. Soc. 2009, 131, 15939-15944.

(36) Suzuki, K.; Morita, H.; Kaneko, T.; Yoshida, H.; Fujimori, H. Crystal structure and magnetic properties of the compound FeN. J. Alloys Compd. 1993, 201, 11-16.

(37) Zhang, H.; Gong, Q.; Ren, S.; Arshid, M. A.; Chu, W.; Chen, C. Implication of iron nitride species to enhance the catalytic activity and stability of carbon nanotubes supported $\mathrm{Fe}$ catalysts for carbon-free hydrogen production via low-temperature ammonia decomposition. Catal. Sci. Technol. 2018, 8, 907-915.

(38) Yin, H.; Zhang, C.; Liu, F.; Hou, Y. Hybrid of Iron Nitride and Nitrogen-Doped Graphene Aerogel as Synergistic Catalyst for Oxygen Reduction Reaction. Adv. Funct. Mater. 2014, 24, 2930-2937.

(39) Hassan, F. M.; Chabot, V.; Li, J.; Kim, B. K.; RicardezSandoval, L.; Yu, A. Pyrrolic-structure enriched nitrogen doped graphene for highly efficient next generation supercapacitors. J. Mater. Chem. A 2013, 1, 2904.

(40) Ma, J.-h.; Wang, L.; Mu, X.; Li, L. Nitrogen-doped graphene supported Pt nanoparticles with enhanced performance for methanol oxidation. Int. J. Hydrogen Energy 2015, 40, 2641-2647.

(41) Choi, C. H.; Park, S. H.; Woo, S. I. Facile growth of N-doped CNTs on Vulcan carbon and the effects of iron content on electrochemical activity for oxygen reduction reaction. Int. J. Hydrogen Energy 2012, 37, 4563-4570.

(42) Zhang, Y.; Xie, Y.; Zhou, Y.; Wang, X.; Pan, K. Well dispersed $\mathrm{Fe}_{2} \mathrm{~N}$ nanoparticles on surface of nitrogen-doped reduced graphite oxide for highly efficient electrochemical hydrogen evolution. J. Mater. Res. 2017, 32, 1770-1776.

(43) Cui, Q.; Chao, S.; Wang, P.; Bai, Z.; Yan, H.; Wang, K.; Yang, $\mathrm{L}$. $\mathrm{Fe}-\mathrm{N} / \mathrm{C}$ catalysts synthesized by heat-treatment of iron triazine carboxylic acid derivative complex for oxygen reduction reaction. RSC Adv. 2014, 4, 12168.

(44) Rohith Vinod, K.; Saravanan, P.; Sakar, M.; Balakumar, S. Insights into the nitridation of zero-valent iron nanoparticles for the facile synthesis of iron nitride nanoparticles. RSC Adv. 2016, 6, 45850-45857.

(45) Oh, Y. J.; Yoo, J. J.; Kim, Y. I.; Yoon, J. K.; Yoon, H. N.; Kim, J.H.; Park, S. B. Oxygen functional groups and electrochemical capacitive behavior of incompletely reduced graphene oxides as a thin-film electrode of supercapacitor. Electrochim. Acta 2014, 116, $118-128$.

(46) Xing, Z.; Ju, Z.; Zhao, Y.; Wan, J.; Zhu, Y.; Qiang, Y.; Qian, Y. One-pot hydrothermal synthesis of Nitrogen-doped graphene as highperformance anode materials for lithium ion batteries. Sci. Rep. 2016, 6, No. 26146.

(47) Azuma, M.; Kashihara, M.; Nakato, Y.; Tsubomura, H. Reduction of oxygen to water on cobalt-nitride thin film electrodes prepared by the reactive if sputtering technique. J. Electroanal. Chem. Interfacial Electrochem. 1988, 250, 73-82.

(48) Gong, K.; Du, F.; Xia, Z.; Durstock, M.; Dai, L. NitrogenDoped Carbon Nanotube Arrays with High Electrocatalytic Activity for Oxygen Reduction. Science 2009, 323, 760-764.

(49) Nagaiah, T. C.; Kundu, S.; Bron, M.; Muhler, M.; Schuhmann, W. Nitrogen-doped carbon nanotubes as a cathode catalyst for the oxygen reduction reaction in alkaline medium. Electrochem. Commun. 2010, 12, 338-341.

(50) Ren, G.; Gao, L.; Teng, C.; Li, Y.; Yang, H.; Shui, J.; Lu, X.; Zhu, Y.; Dai, L. Ancient Chemistry "Pharaoh's Snakes" for Efficient $\mathrm{Fe}-/ \mathrm{N}$-Doped Carbon Electrocatalysts. ACS Appl. Mater. Interfaces 2018, 10, 10778-10785.

(51) Susi, T.; Pichler, T.; Ayala, P. X-ray photoelectron spectroscopy of graphitic carbon nanomaterials doped with heteroatoms. Beilstein J. Nanotechnol. 2015, 6, 177-192.
(52) Wu, Z. S.; Yang, S.; Sun, Y.; Parvez, K.; Feng, X.; Mullen, K. 3D nitrogen-doped graphene aerogel-supported $\mathrm{Fe} 3 \mathrm{O} 4$ nanoparticles as efficient electrocatalysts for the oxygen reduction reaction. J. Am. Chem. Soc. 2012, 134, 9082-9085.

(53) Davis, R. E.; Horvath, G. L.; Tobias, C. W. The solubility and diffusion coefficient of oxygen in potassium hydroxide solutions. Electrochim. Acta 1967, 12, 287-297.

(54) Marković, N. M.; Gasteiger, H. A.; Ross, P. N. Oxygen Reduction on Platinum Low-Index Single-Crystal Surfaces in Alkaline Solution: Rotating Ring DiskPt(hkl) Studies. J. Phys. Chem. 1996, 100, 6715-6721.

(55) Asahi, M.; Yamazaki, S.; Itoh, S.; Ioroi, T. Electrochemical reduction of dioxygen by copper complexes with pyridylalkylamine ligands dissolved in aqueous buffer solution: the relationship between activity and redox potential. Dalton Trans. 2014, 43, 10705-10709.

(56) Li, Y.; Kuttiyiel, K. A.; Wu, L.; Zhu, Y.; Fujita, E.; Adzic, R. R.; Sasaki, K. Enhancing Electrocatalytic Performance of Bifunctional Cobalt-Manganese-Oxynitride Nanocatalysts on Graphene. ChemSusChem 2017, 10, 68-73.

(57) Vikkisk, M.; Kruusenberg, I.; Ratso, S.; Joost, U.; Shulga, E.; Kink, I.; Rauwel, P.; Tammeveski, K. Enhanced electrocatalytic activity of nitrogen-doped multi-walled carbon nanotubes towards the oxygen reduction reaction in alkaline media. RSC $A d v$. 2015, 5, 59495-59505.

(58) Jukk, K.; Kongi, N.; Rauwel, P.; Matisen, L.; Tammeveski, K. Platinum Nanoparticles Supported on Nitrogen-Doped Graphene Nanosheets as Electrocatalysts for Oxygen Reduction Reaction. Electrocatalysis 2016, 7, 428-440.

(59) Molina-García, M. A.; Rees, N. V. Effect of catalyst carbon supports on the oxygen reduction reaction in alkaline media: a comparative study. RSC Adv. 2016, 6, 94669-94681.

(60) Wang, M.; Yang, Y.; Liu, X.; Pu, Z.; Kou, Z.; Zhu, P.; Mu, S. The role of iron nitrides in the Fe-N-C catalysis system towards the oxygen reduction reaction. Nanoscale 2017, 9, 7641-7649.

(61) Varnell, J. A.; Sotiropoulos, J. S.; Brown, T. M.; Subedi, K.; Haasch, R. T.; Schulz, C. E.; Gewirth, A. A. Revealing the Role of the Metal in Non-Precious-Metal Catalysts for Oxygen Reduction via Selective Removal of Fe. ACS Energy Lett. 2018, 3, 823-828.

(62) Lai, L.; Potts, J. R.; Zhan, D.; Wang, L.; Poh, C. K.; Tang, C.; Gong, H.; Shen, Z.; Lin, J.; Ruoff, R. S. Exploration of the active center structure of nitrogen-doped graphene-based catalysts for oxygen reduction reaction. Energy Environ. Sci. 2012, 5, 7936.

(63) Ge, X.; Sumboja, A.; Wuu, D.; An, T.; Li, B.; Goh, F. W. T.; Hor, T. S. A.; Zong, Y.; Liu, Z. Oxygen Reduction in Alkaline Media: From Mechanisms to Recent Advances of Catalysts. ACS Catal. 2015, 5, 4643-4667.

(64) Ramaswamy, N.; Mukerjee, S. Fundamental Mechanistic Understanding of Electrocatalysis of Oxygen Reduction on Pt and Non-Pt Surfaces: Acid versus Alkaline Media. Adv. Phys. Chem. 2012, 2012, 1-17.

(65) Liu, J.; Li, E.; Ruan, M.; Song, P.; Xu, W. Recent Progress on $\mathrm{Fe} / \mathrm{N} / \mathrm{C}$ Electrocatalysts for the Oxygen Reduction Reaction in Fuel Cells. Catalysts 2015, 5, 1167-1192.

(66) Liu, Y.-L.; Xu, X.-Y.; Shi, C.-X.; Ye, X.-W.; Sun, P.-C.; Chen, T.$\mathrm{H}$. Iron-nitrogen co-doped hierarchically mesoporous carbon spheres as highly efficient electrocatalysts for the oxygen reduction reaction. RSC Adv. 2017, 7, 8879-8885.

(67) Hummers, W. S.; Offeman, R. E. Preparation of Graphitic Oxide. J. Am. Chem. Soc. 1958, 80, 1339. 